\title{
Different properties of mammary carcinogenesis induced by two chemical carcinogens, DMBA and PhIP, in heterozygous BALB/c Trp53 knockout mice
}

\author{
YUKINO MACHIDA $^{1,2}$ and TOSHIO IMAI ${ }^{1}$ \\ ${ }^{1}$ Central Animal Division, National Cancer Center Research Institute, Tokyo 104-0045; \\ ${ }^{2}$ Department of Veterinary Pathology, Nippon Veterinary and Life Science University, Tokyo 180-8602, Japan
}

Received April 8, 2021; Accepted July 2, 2021

DOI: 10.3892/ol.2021.12999

\begin{abstract}
Chemical carcinogens, such as 7,12-dimethylbenz[a] anthracene (DMBA) and 2-amino-1-methyl-6-phenylimid azo(4,5-b)pyridine (PhIP), are known to induce mammary carcinomas in mice and rats. In the present study, the phenotypic and genotypic characteristics of carcinogen-induced mammary carcinogenesis in heterozygous BALB/c tumor protein p53 (Trp53) knockout mice were examined with reference to published data surrounding human breast cancer. A significantly accelerated induction of mammary carcinomas was observed following a single dose of DMBA $(50 \mathrm{mg} / \mathrm{kg}$ of body weight at 7 weeks of age), and a modest acceleration was induced by $\mathrm{PhIP}(50 \mathrm{mg} / \mathrm{kg}$ of body weight) administered by gavage 6 times/2 weeks from 7 weeks of age. DMBA-induced mammary carcinomas were histopathologically characterized by distinct biphasic structures with luminal and myoepithelial cells, as well as a frequent estrogen receptor expression, and PhIP-induced carcinomas with solid/microacinar structures consisted of pleomorphic cells. Of note, DMBA-induced mammary carcinomas were characterized by a HRas proto-oncogene (Hras) mutation at codon 61, and gene/protein expression indicating MAPK stimulation. PhIP-induced lesions were suspected to be caused by different molecular mechanisms, including Wnt/ $\beta$-catenin signaling and/or gene mutation-independent PI3K/AKT signaling activation. In conclusion, the present mouse mammary carcinogenesis models, induced by a combination of genetic and exogenous factors, may be utilized (such as the DMBA-induced model with Trp53 gene function deficiency as a model of adenomyoepithelioma, characterized by distinct biphasic cell constituents
\end{abstract}

Correspondence to: Dr Toshio Imai, Central Animal Division, National Cancer Center Research Institute, 5-1-1 Tsukiji, Tokyo 104-0045, Japan

E-mail: toimai@ncc.go.jp

Key words: 7,12-dimethylbenz[a]anthracene, ductal carcinoma, HRas proto-oncogene, mammary glands, mice, myoepithelioma, 2-amino-1methyl-6-phenylimidazo(4,5-b)pyridine, tumor protein $\mathrm{p} 53$ and Hras mutations), but PhIP-induced models are required to further analyze the genetic/epigenetic mechanisms promoting mammary carcinomas.

\section{Introduction}

Breast cancer is the most common malignancy in young women (20-39 year of age) worldwide (1). In the United States, a small but significant increase in the incidence of metastatic breast cancer in women aged 25-39 years has been recorded, without a corresponding increase in the incidence in older women (2). Although the incidence and mortality rates associated with hormone receptor (HR)-negative breast cancer have been decreasing, those of HR-positive breast cancer have been increasing in the United States, likely in part due to the increasing prevalence of excess body weight and declining fertility rates (3). On the other hand, young adult patients with breast cancer (aged $<35$ years) have a poor prognosis in Japan, independent of prognostic clinicopathological factors (4). Therefore, basic and translational studies for the development of prevention strategies for breast cancer at younger ages are required.

Chemically-induced rats have frequently been used as animal models of HR-positive breast cancer $(5,6)$. In addition to chemically-induced mammary carcinomas, mouse models of estrogen receptor (ER)1, cyclin D1, prolactin, transforming growth factor $\alpha$, nuclear receptor coactivator 3 , extra spindle pole bodies like 1 , separase and Wnt family member 1 overexpression, phosphatidylinositol-4,5-bisphosphate 3-kinase catalytic subunit $\alpha$ (Pik3ca) gain-of-function, and tumor protein p53 (Trp53) or signal transducer and activator of transcription 1 loss, were also found to be associated with ER-positive-mammary carcinogenesis (7).

As aforementioned, several mammary tissue-targeting genotoxic carcinogens have been used for the induction of mammary carcinogenesis in rat models. The experimental polycyclic aromatic hydrocarbon 7,12-dimethylbenz[a]anthracene (DMBA) is a potent and well-established mammary gland carcinogen in rats $(8,9)$, and DMBA-induced adenocarcinomas were previously shown to originate from both luminal and myoepithelial cells (5). DMBA was also reported to induce mammary carcinomas in CD2F1 (BALB/c x DBA/2) (10) and 
B6D2F1 (C57BL/6 x DBA/2) mice (11), and DMBA-induced mammary adenocarcinomas were shown to be primarily composed of luminal cells and residual myoepithelial-like cells $(10,11)$, or mainly of myoepithelial cells (11). 2-Amino-1 -methyl-6-phenylimidazo(4,5-b)pyridine (PhIP) is a heterocyclic amine found in cooked meat that potently induces tumors not only in the mammary glands, but also in the colon and prostate of rats (12-14). PhIP-induced mammary tumors exhibited a dose-dependent increase in malignant phenotypes (12), and in combination with a high-fat diet (HFD), PhIP was reported to enhance malignant alterations in rats (15). In addition, HFD and high-sucrose diets, administered from the start of animal growth till the end of the study, were reported to stimulate mammary tumor development in experimental rat and mouse models (16-18). Furthermore, a limited-duration HFD (e.g., during fetal/suckling stages) has been demonstrated to affect mammary tumorigenesis $(19,20)$. These carcinogens and nutrient factors have also been epidemiologically reported as risk factors for breast cancer (21-23).

The mutation and loss of function of p53 are common features among types of human breast cancer, and heterozygous BALB/c Trp53 knockout mice have been reported as a spontaneous mammary carcinoma model $(24,25)$. The aim of the present study was to confirm whether DMBA or PhIP promoted short-latency mammary carcinoma in heterozygous BALB/c Trp53 knockout mice, and to investigate the phenotypic and genotypic characteristics of the induced carcinomas with reference to published data of human breast cancer.

\section{Materials and methods}

Mice. Heterozygous $\mathrm{C} 3 \mathrm{H}$ Trp53 knockout mice, in which the $\mathrm{Nco}$ I site in exon 2 of the p53 gene was heterozygously inserted by a neomycin phosphotransferase gene (26), were obtained from RIKEN BioResource Center (identification no. RBRC00107) and crossed with BALB/c mice (BALB/cAJcl; CLEA Japan, Inc.) for 5 (N5) or 9 (N9) generations. A total of $34 \mathrm{~N} 5$ mice (body weight,14.0-24.9 $\mathrm{g}$ at 5 weeks of age) and 75 N9 mice (body weight, 18.9-29.0 g at 5 weeks of age) were used in the present study. The mice were housed in plastic cages with woodchip bedding ( $n \leq 5$ per cage) in an air-conditioned animal room maintained at $22^{\circ} \mathrm{C}$ (fluctuation range, within $1^{\circ} \mathrm{C}$ ) and $55 \%$ relative humidity (fluctuation range, within $10 \%$ ) on a 12:12-h light-dark cycle, and given free access to the standard chow diet CE2 or beef tallow-based HFD Quick Fat (both CLEA Japan, Inc.), and tap water or $10 \%$ sucrose (Wako Pure Chemical Industries, Ltd.) water (SW) during the period of 5-10 weeks of age. However, as the number of animals in the control, HFD and SW groups was small, no notable effects pertaining to nutrient factors were observed among the mice; therefore, all groups were evaluated as a whole in order to reach a conclusion regarding the phenotypic and genotypic characteristics of DMBA- or PhIP-induced mammary carcinomas in heterozygous BALB/c Trp53 knockout mice. Mouse experiments were carried out in a specific pathogen-free environment at the animal facility of the National Cancer Center Research Institute (Tokyo, Japan), according to the institutional guidelines, and following the approval of the National Cancer Center Animal Ethics Committee in Japan (approval no. T17-028-C02).
Induction of mammary carcinomas. To investigate the characteristics of mammary tumors induced by DMBA (MilliporeSigma), BALB/c Trp53 heterozygous N9 female knockout mice were administered a single dose of DMBA (50 mg/kg of bodyweight, $\mathrm{n}=20)$ and its vehicle, sesame oil (10 $\mathrm{ml} / \mathrm{kg}$ body weight, $\mathrm{n}=20$; MilliporeSigma). N5 female mice were administered PhIP (Wako Pure Chemical Industries, Ltd.) 6 times $/ 2$ weeks $(50 \mathrm{mg} / \mathrm{kg}$ of bodyweight, $\mathrm{n}=34)$. Both chemicals were administered by gavage at 7 weeks of age. The present dose setting was based on reported oral doses for the induction of mammary tumors in rats; a single oral dose of DMBA (50 mg/kg of body weight) (27) and multiple oral doses of PhIP (25-85 mg/kg of body weight) (28-30) to adolescent female Sprague-Dawley rats induced mammary adenocarcinomas within 20-30 weeks. In the present experiments, groups of BALB/c Trp53 wild-type mice with $(\mathrm{n}=20)$ and without $(n=15)$ DMBA administration were used to confirm susceptibility to mammary carcinogenesis. In our previous study, no obvious changes in histopathological characteristics and the ER-positive frequency of spontaneous mammary adenocarcinomas were detected in generations $\mathrm{F} 1$ (first filial generation) to $\mathrm{N} 4$ in $\mathrm{BALB} / \mathrm{c}$ crossed with $\mathrm{C} 3 \mathrm{H}$ heterozygous Trp53 knockout mice (24). Therefore, the effects of DMBA and PhIP on the characteristics of induced mammary adenocarcinomas were independently evaluated from the numbers of the backcross generations. During the experimental period, anatomic regions containing mammary tissue, such as the cervix, thorax and abdomen, were palpated weekly to detect subcutaneous nodules. When nodules accounted for $>10 \%$ of the body weight of mice [the longest nodule diameter measured using calipers often exceeded $15 \mathrm{~mm}$ (31)] or general conditions were poor, the mice were euthanized by isoflurane overdose, and the inguinal mammary gland (fat pad), subcutaneous nodules and organs/tissues with abnormalities in the abdominal and thoracic cavities were excised, followed by fixing with $10 \%$ neutrally buffered formalin. The pieces of subcutaneous nodules and fat pad with mammary glands were stored in liquid nitrogen.

Histopathology and immunohistochemistry (IHC). The samples were fixed with $10 \%$ neutral buffered formalin at room temperature for 1-2 days, and then cut at the maximum cutting plane, processed routinely and embedded in paraffin wax. Sections (thickness, $3 \mu \mathrm{m}$ ) were stained with hematoxylin and eosin (H\&E) and histopathologically evaluated using a transmission light microscope (BX51; Olympus Corporation). Histopathological phenotypes of the DMBA- or PhIP-induced carcinomas were classified into the following subtypes: i) Glandular/microacinar, tumor composed of glands and/or microacinar formation; ii) papillary, tumor with finger-like projections composed of epithelium covering a central fibrovascular core; and iii) solid, tumor is composed of solid sheets of epithelial cells with little or no glandular differentiation $(32,33)$. Inasmuch as distinct biphasic structures with luminal and myoepithelial cells were observed in the DMBA-induced carcinomas, a scoring system was generated in the present study, by classification and grading based on the area occupied by the biphasic structures: 0-4, 5-24, 25-49, 50-74 and 75-100\% were graded as 0, 1, 2, 3 and 4 , respectively. Serial sections were subjected to IHC, where a total of 10 DMBA- and PhIP-treated samples obtained 
from heterozygous Trp53 knockout mice were preferentially selected from large carcinomas. For antigen retrieval, the sections were autoclaved at $121^{\circ} \mathrm{C}$ for $10 \mathrm{~min}$ in $0.01 \mathrm{M}$ citrate buffer ( $\mathrm{pH}$ 6.0), after deparaffinization. Then, the sections were incubated with $3 \%$ hydrogen peroxide (at room temperature for $10 \mathrm{~min}$ ), $10 \%$ normal goat serum (at room temperature for $20 \mathrm{~min}$.; Nichirei Biosciences, Inc.), and with the following primary antibodies $4^{\circ} \mathrm{C}$ overnight: Anti-human $\mathrm{ER} \alpha$ mouse monoclonal (1:50 dilution; clone 6F11; cat. no. NCL-ER-6F11; Novocastra), anti-human/mouse phosphorylated-ERK1(pERK1; T202/Y204)/ERK2 (pERK2; T185/Y187) rabbit polyclonal (1:500 dilution; cat. no. AF1018; R\&D Systems, Inc.), anti-human dual-specificity phosphatase (DUSP)4 rabbit polyclonal (1:50 dilution, cat. no. ab72593; Abcam) anti-human phosphorylated-AKT (pAKT; Ser473) rabbit monoclonal (1:100 dilution; clone D9E; cat. no. \#4060; Cell Signaling Technology, Inc.), anti-mouse $\beta$-catenin mouse monoclonal (1:500 dilution; clone 14; cat. no. 610154; BD Transduction Laboratories), anti-human cytokeratin 18 rabbit polyclonal (1:1,000 dilution; cat. no. 10830-1-AP; ProteinTech Group, Inc.), anti-human $\alpha$-smooth muscle actin ( $\alpha$ SMA) rabbit monoclonal (1:1,000 dilution; clone EPR5368; cat. no. ab124964; Abcam) and anti-rat proliferating cell nuclear antigen (PCNA) mouse monoclonal (1:800 dilution; clone PC10; cat. no. M0879; DakoCytomation). The sections were incubated with Histofine MAX PO solution (Nichirei Biosciences, Inc.). Antibody binding was visualized using 3,3'-diaminobenzidine tetrahydrochloride or New Fuchsin Substrate kit (Nichirei Biosciences, Inc.), and sections were routinely counterstained with hematoxylin at room temperature. Negative controls without primary antibodies were set for each antigen.

Direct DNA sequencing. DNA was extracted from frozen normal mammary (fat pad) and mammary carcinoma tissues with NucleoSpin Tissue (cat. no. 740952; Macherey-Nagel $\mathrm{GmbH}$ ) according to the manufacturer's instructions; 10 of the same samples used for IHC in each group were analyzed. PCR products of HRas proto-oncogene (Hras) exon 2, codon 61, which was expected to harbor DMBA-induced mutations, as observed in rat mammary carcinomas $(34,35)$, and Pik3ca exons 6,7,9 and 20, in which hotspot mutations have frequently been observed in human breast cancer (36), were obtained for mutation analysis using the primers shown in Fig. S1A. The sequencing reaction was performed using the BigDye Terminator v3.1 Cycle Sequencing kit (cat. no. 4337455; Thermo Fisher Scientific, Inc.) per the manufacturers protocol. For the sequencing reaction of each target gene, PCR product ( $\sim 0.1$ pmoles, which was estimated from the electrophoretic band density) was used as a template, and the forward or reverse primer for the PCR reaction was applied; however, an additional reverse sequencing reaction was performed in cases where the obtained result in the first reaction needed to be confirmed. The sequences were determined using a 3130XL Genetic Analyzer (Thermo Fisher Scientific, Inc.), and analyzed with SnapGene software version 3.1.4 (Insightful Science, LLC).

Reverse transcription-quantitative (RT-q) PCR. RNA was extracted from frozen normal mammary or carcinoma tissues using ISOGEN with Spin Column (Nippon Gene Co., Ltd.). cDNA was synthesized from RNA using the High-Capacity cDNA Reverse Transcription kit (Thermo Fisher Scientific, Inc.). A total of 10 samples of the same cases used for IHC in each group were analyzed. qPCR was performed with TaqMan probes: The dual-specificity phosphatase 4 (Dusp4) gene (Assay ID Mm00723761_m1; cat. no. 4331182; Thermo Fisher Scientific, Inc.) encoding DUSP4, actin $\beta$ (Actb) gene (Assay ID Mm02619580_g1; cat. no. 4331182; Thermo Fisher Scientific, Inc.) encoding $\beta$-actin and TaqMan Fast Universal PCR master mix (Thermo Fisher Scientific, Inc.) using the ABI-OneStep PCR system (Thermo Fisher Scientific, Inc.). Thermocycling conditions were as follows: Initial denaturation, $95^{\circ} \mathrm{C}$ for $20 \mathrm{sec}$; 40 cycles of amplification (denaturation, $95^{\circ} \mathrm{C}$ for $1 \mathrm{sec}$; annealing/extension, $60^{\circ} \mathrm{C}$ for $20 \mathrm{sec}$ ). Values were normalized to the expression of the Actb gene and calculated by the $2^{-\Delta \Delta \mathrm{Cq}}$ method (37).

Statistical analysis. Significant differences in the incidence of histopathological findings were determined using Fisher's exact test. For quantitative data from RT-qPCR for Dusp4 gene expression, results are presented as the mean \pm SEM, and differences between groups were analyzed using the Kruskal-Wallis test, followed by Steel's multiple comparison test using EZR (Easy R) software, version 4.0.2 (38). $\mathrm{P}<0.05$ was considered to indicate a statistically significant difference.

\section{Results}

Accelerated induction of mammary carcinomas by DMBA and $P h I P$. Mammary carcinomas were first identified by palpation in the subcutaneous tissues of the cervix, thorax and/or inguinal regions of 2/20 heterozygous Trp53 knockout mice on week 19 post-DMBA administration, and the number of tumor-bearing DMBA-treated mice gradually increased thereafter. The cumulative numbers of palpable nodules histopathologically diagnosed as mammary carcinomas are presented in Fig. 1A. The DMBA-treated and vehicle control groups were euthanized at 26 weeks. The incidence of histopathologically diagnosed mammary carcinomas, including intraductal carcinomas in the DMBA group, was 15/20 (75.0\%), and additional dysplastic ductal hyperplasia was observed in 3/20 (15.0\%) mice on week 26 post-DMBA administration (Table I). The number of identified mammary carcinomas were $1,2,3$ and 4/mouse in 4, 2, 3 and 6 DMBA-treated mice, respectively. On the other hand, mammary carcinomas were not observed in the vehicle sesame oil-treated control group without DMBA administration until 26 weeks after vehicle administration (Table I). The incidence of mammary tumors was significantly higher in DMBA-treated heterozygous Trp53 knockout mice than in DMBA-treated wild-type mice $(\mathrm{P}<0.001)$. In addition to the identified mammary carcinomas, malignant lymphomas were found in 3/20 (15.0\%), and lung adenocarcinomas in 1/20 (5\%) heterozygous Trp53 knockout mice each with and without DMBA administration, respectively; other tumors, including endometrial stromal sarcomas and granulosa cell tumors, were found in DMBA-treated Trp53 heterozygous knockout or wild-type mice with DMBA administration. The results indicate that the incidence of mammary carcinomas was significantly increased in DMBA-treated Trp53 heterozygous 
Table I. Incidences of mammary carcinomas and hyperplastic lesions in BALB/c-Trp53 heterozygous knockout mice as well as BALB/c-Trp53-wild-type mice with and without DMBA/PhIP administration.

\begin{tabular}{|c|c|c|c|c|c|}
\hline \multirow[b]{2}{*}{ Group } & \multicolumn{2}{|c|}{$\begin{array}{c}\text { Trp53 heterogenous } \\
\text { knockout mice, n }(\%)\end{array}$} & \multicolumn{2}{|c|}{$\begin{array}{l}\text { Trp53-wild-type } \\
\text { mice, n (\%) }\end{array}$} & \multirow{2}{*}{$\begin{array}{c}\begin{array}{c}\text { Trp53 heterogenous } \\
\text { knockout mice, n (\%) }\end{array} \\
\text { PhIP }^{\mathrm{a}} \\
\mathrm{N}=34\end{array}$} \\
\hline & $\begin{array}{c}\text { DMBA } \\
\mathrm{N}=20\end{array}$ & $\begin{array}{l}\text { Vehicle } \\
\mathrm{N}=20\end{array}$ & $\begin{array}{c}\text { DMBA } \\
\mathrm{N}=20\end{array}$ & $\begin{array}{l}\text { Vehicle } \\
\mathrm{N}=15\end{array}$ & \\
\hline Mammary carcinoma & $14(70)^{\mathrm{b}}$ & 0 & $0(0)$ & $1(7)$ & $12(35)$ \\
\hline Intraductal carcinoma & $1(5)^{b}$ & 0 & $3(15)$ & 0 & $2(6)$ \\
\hline Dysplastic ductal hyperplasia & $3(15)$ & 0 & 0 & 0 & 0 \\
\hline
\end{tabular}

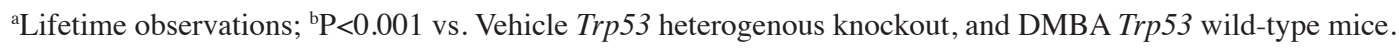
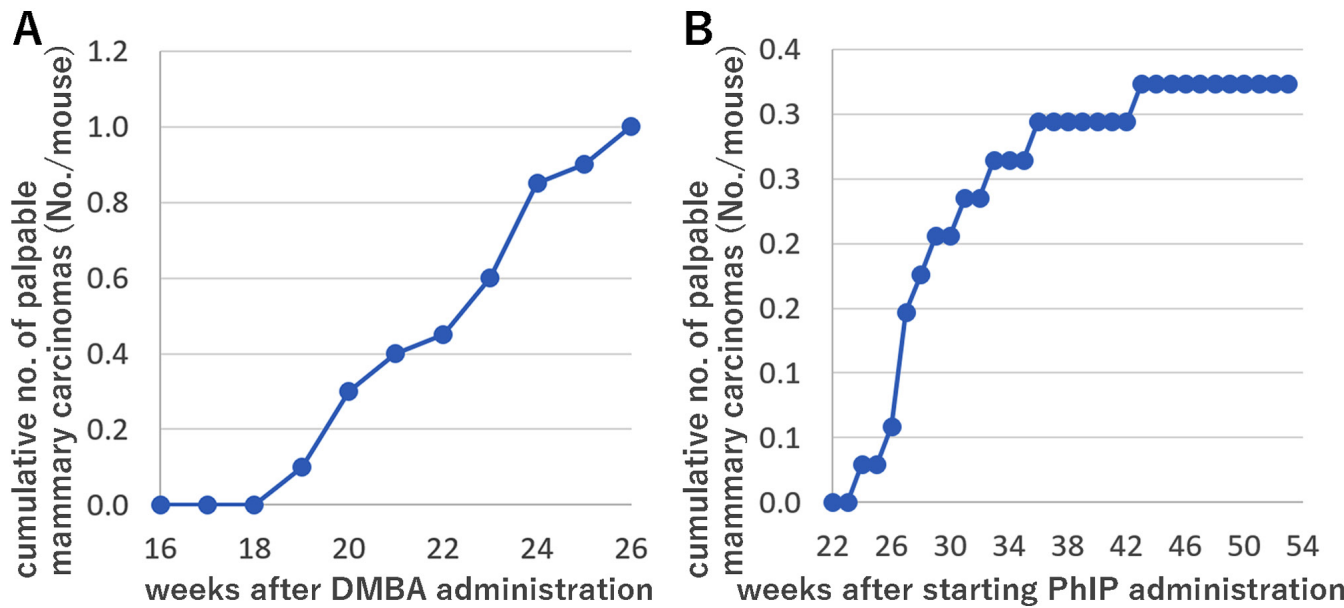

Figure 1. Cumulative mean number of palpable mammary carcinomas in (A) DMBA- and (B) PhIP-treated heterozygous Trp53 knockout mice. DMBA, 7,12-dimethylbenz[a]anthracene; PhIP, 2-amino-1-methyl-6-phenylimidazo(4,5-b)pyridine; Trp53, tumor protein p53.

knockout mice, compared with the vehicle controls, by week 26 post-DMBA administration.

In PhIP-treated BALB/c heterozygous Trp53 knockout mice, palpable mammary carcinomas were observed in only $2 / 34(6 \%)$ mice 26 weeks from the commencement of PhIP administration. Therefore, lifetime observations were conducted for the PhIP-treated group. The cumulative numbers of palpable nodules histopathologically diagnosed as mammary carcinomas are presented in Fig. 1B. Palpable mammary carcinomas and tumors in other organs and tissues were identified on weeks 24-53 from the commencement of PhIP administration. The incidence of histopathologically diagnosed mammary carcinomas, including intraductal carcinomas, was $14 / 34$ (41\%; Table I) and the median latency period was 33-34 weeks from the commencement of PhIP administration. A single mammary carcinoma was diagnosed per mouse. The incidence of tumors in other organs/tissues [adrenal subcapsular cell carcinomas in 9/34 (26\%) mice, malignant lymphomas in 6/34 (18\%) mice, histiocytic sarcomas and osteosarcomas in 4/34 (12\%) mice] was cumulatively higher than that of mammary carcinomas in the PhIP-treated groups. In summary, the median latency period from the commencement of PhIP administration was shorter than that for spontaneous cases during the lifetime observation of heterozygous BALB/c Trp53 knockout mice without PhIP administration.

DMBA-induced mammary carcinomas are histopathologically characterized by biphasic structures and PhIP-induced solid/microacinar-type carcinomas. Mammary carcinomas induced in the DMBA-treated heterozygous Trp53 knockout mice histopathologically exhibited highly differentiated glandular structures (Fig. 2A). They featured a characteristic biphasic structure consisting of two differentiation types of inner luminal and outer myoepithelial cells. Immunohistochemically, inner cells were positive for cytokeratin 18 and negative for aSMA. Outer cells were positive for $\alpha$ SMA (Fig. 2B). Each $\mathrm{H} \& \mathrm{E}$-stained specimen was classified into 5 grades, based on the area occupied by the biphasic structures: 0-4, 5-24, 25-49, $50-74$ and $75-100 \%$ were graded as $0,1,2,3$ and 4 , respectively. Among the selected 10 large carcinoma samples from the DMBA-treated heterozygous Trp53 knockout mice, 0, 2, 2, 1 and 5 samples were classified as grades $0,1,2,3$ and 4, respectively.

The results of IHC for signaling molecules in the DMBA-treated heterozygous Trp53 knockout mice are shown in Fig. 2D-2I and summarized in Fig. 2J. In H\&E-stained specimens, inner luminal cells in each biphasic glandular 


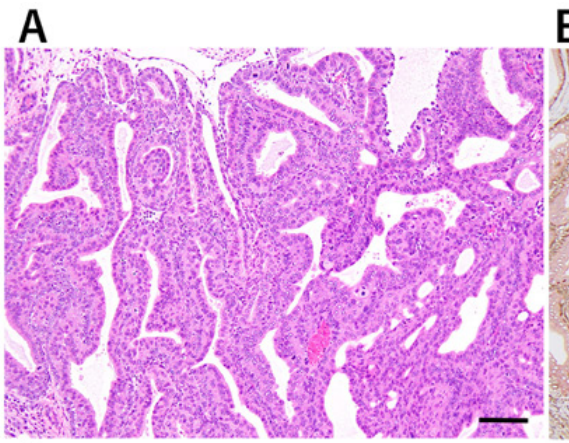

B
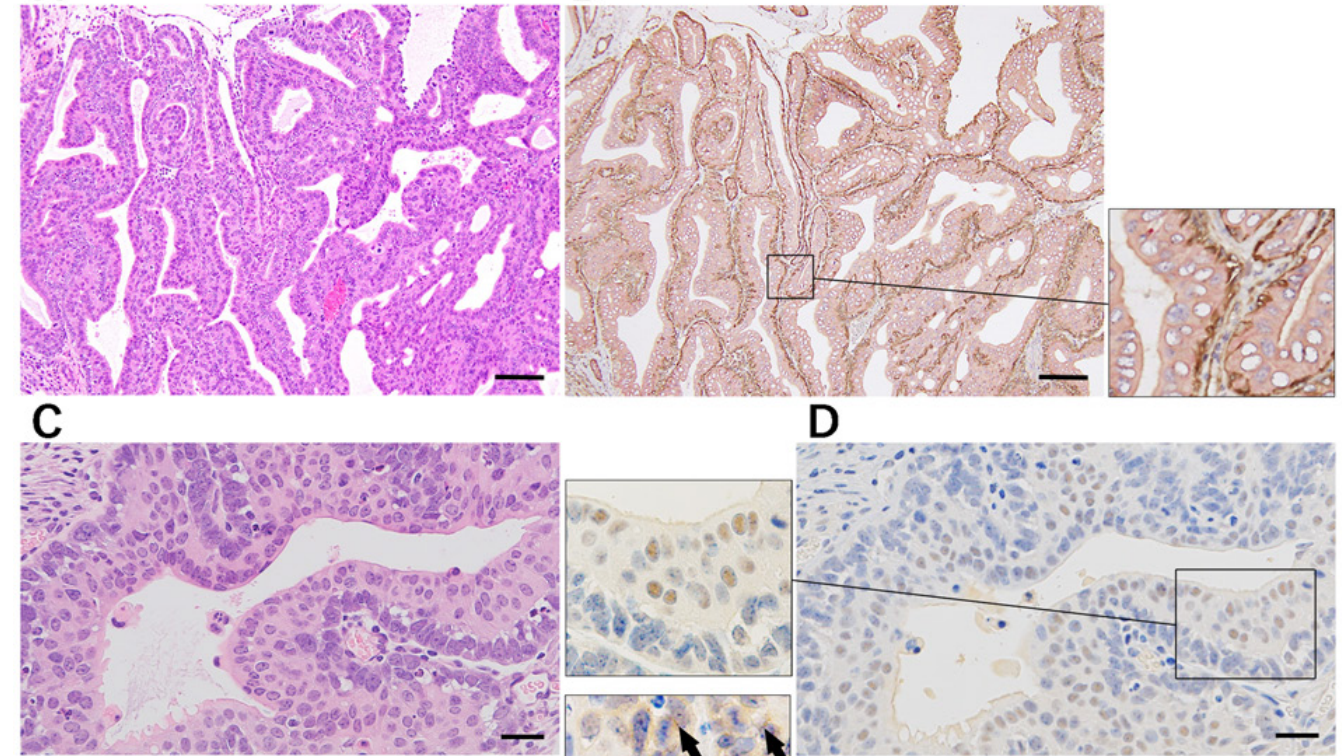

D

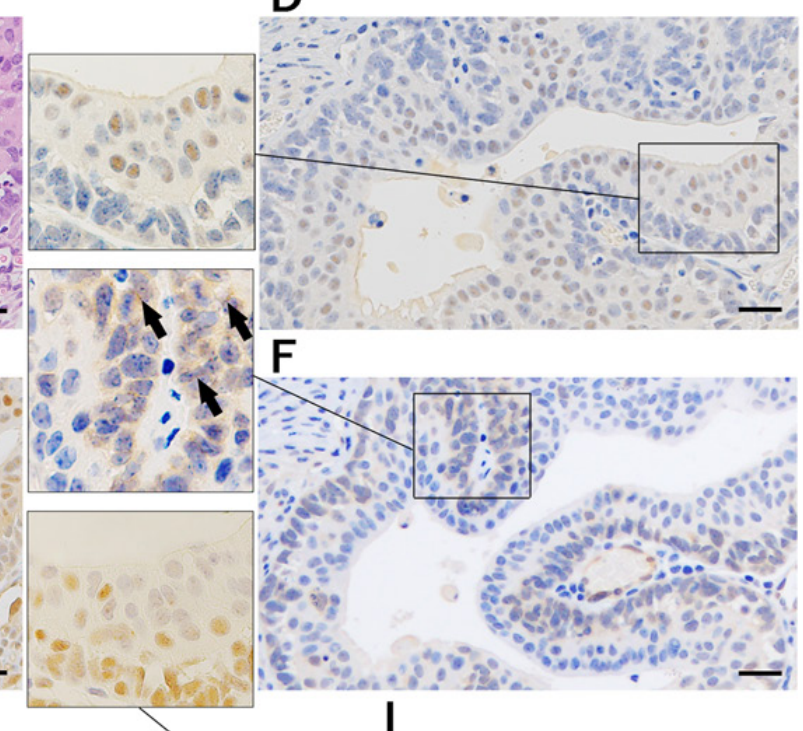

\section{G}

$\mathrm{H}$ I

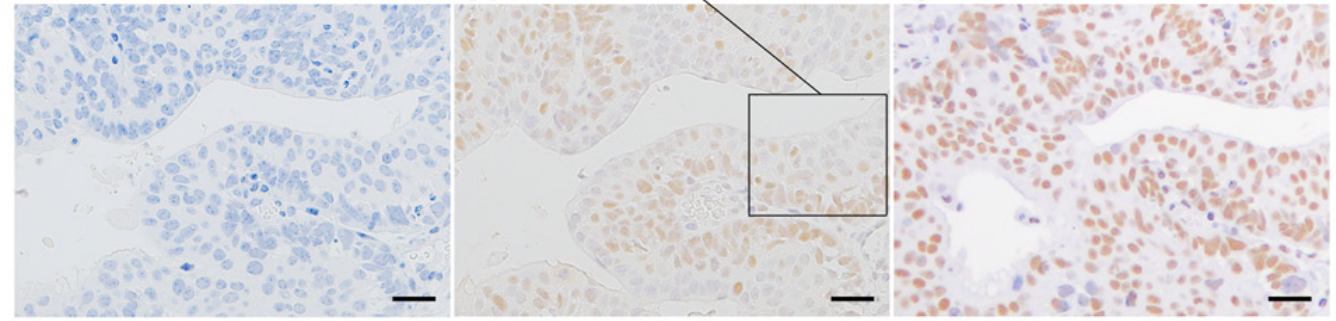

J

Summary of immunohistochemical analysis

\begin{tabular}{lcccccccccc}
\hline Sample \# & 1 & 2 & 3 & 4 & 5 & 6 & 7 & 8 & 9 & 10 \\
\hline ER $\alpha$ & $\mathrm{N}$ & $\mathrm{N}$ & $\mathrm{N}$ & $\mathrm{N}$ & $\mathrm{N}$ & $\mathrm{N}$ & $\mathrm{N}$ & $\mathrm{N}$ & $\mathrm{N}$ & $\mathrm{N}$ \\
pERK1/2 & $\mathrm{N}$ & $\mathrm{N}$ & $\mathrm{N}$ & $\mathrm{N}$ & $\mathrm{N}$ & $\mathrm{N}$ & $\mathrm{N}$ & $\mathrm{CN}$ & $\mathrm{N}$ & $\mathrm{CN}$ \\
pAKT & - & - & - & - & - & - & - & - & - & - \\
$\beta$-catenin & $\mathrm{M}$ & $\mathrm{M}$ & $\mathrm{M}$ & $\mathrm{M}$ & $\mathrm{M}$ & $\mathrm{M}$ & $\mathrm{M}$ & $\mathrm{M}$ & $\mathrm{MC}$ & $\mathrm{MC}$ \\
\hline
\end{tabular}

Figure 2. (A) Mammary carcinomas induced in the DMBA-treated heterozygous Trp53 knockout mice exhibited highly differentiated glandular structures (H\&E staining; scale bar, $50 \mu \mathrm{m}$ ), and (B) featured a characteristic biphasic structure consisting of two differentiation types of luminal (red; cytokeratin 18) and myoepithelial cells (brown; $\alpha \mathrm{SMA}$ ); the lower right box is a higher magnification image of the lower middle box. (C) H\&E staining; scale bar, $20 \mu \mathrm{m}$. (D) Immunohistochemistry for estrogen receptor $\alpha$ revealed $\mathrm{N}$ positivity in the inner carcinoma cells; the middle left box is a higher magnification image of the middle right box. (E) N positivity for pERK was primarily present in inner cells. (F) M positivity for $\beta$-catenin was weak in outer cells (arrows); the upper left box is a higher magnification image of the upper left box. (G) pAKT was negative. (H) Proliferating cell nuclear antigen positivity was primarily present in outer cells; the upper box is a higher magnification image of the middle right box. (I) N positivity for dual-specificity phosphatase was present in both inner and outer cells. (J) Summary of immunohistochemical analysis of mammary carcinomas in DMBA-treated Trp53 heterozygous knockout mice. DMBA, 7,12-dimethylbenz[a]anthracene; N, nuclear; M, membranous. H\&E, hematoxylin and eosin; $\alpha$ SMA, $\alpha$-smooth muscle actin.

structure exhibited an abundant eosinophilic cytoplasm and large nucleus. Outer myoepithelial cells exhibited a scant basophilic cytoplasm (Fig. 2C). IHC for ER $\alpha$ revealed nuclear $(\mathrm{N})$ positivity in the inner cells (Fig. 2D). ER $\alpha$-positive carcinomas were identified in 10/10 DMBA-treated mice. pERK showed $\mathrm{N}$ positivity and cytoplasmic and nuclear $(\mathrm{CN})$ positivity in the peripheral area of the nodules, with $\mathrm{N}$ positivity prominent (8/10; Fig. $2 \mathrm{E})$. IHC for $\beta$-catenin revealed membranous (M) and membranous and cytoplasmic (MC) positivity in the carcinoma cells, with $\mathrm{M}$ positivity prominent (8/10; Fig. 2F). No DMBA-treated mice were pAKT-positive (Fig. 2G). In all DMBA-treated mice, PCNA positivity 


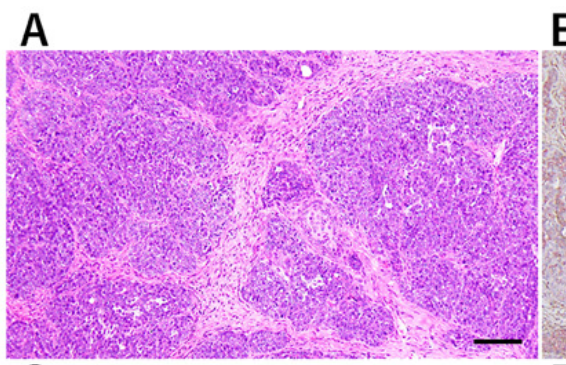

B

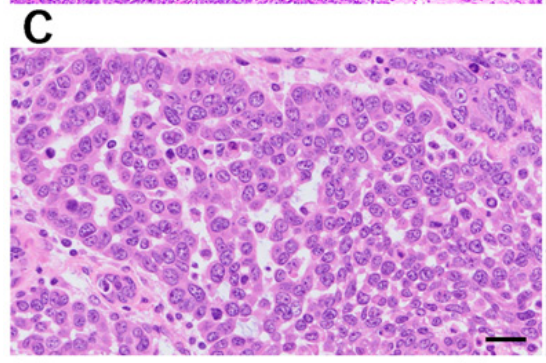

D

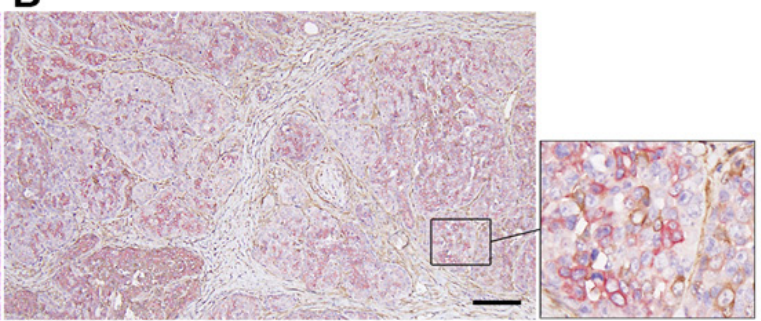

$\mathbf{E}$
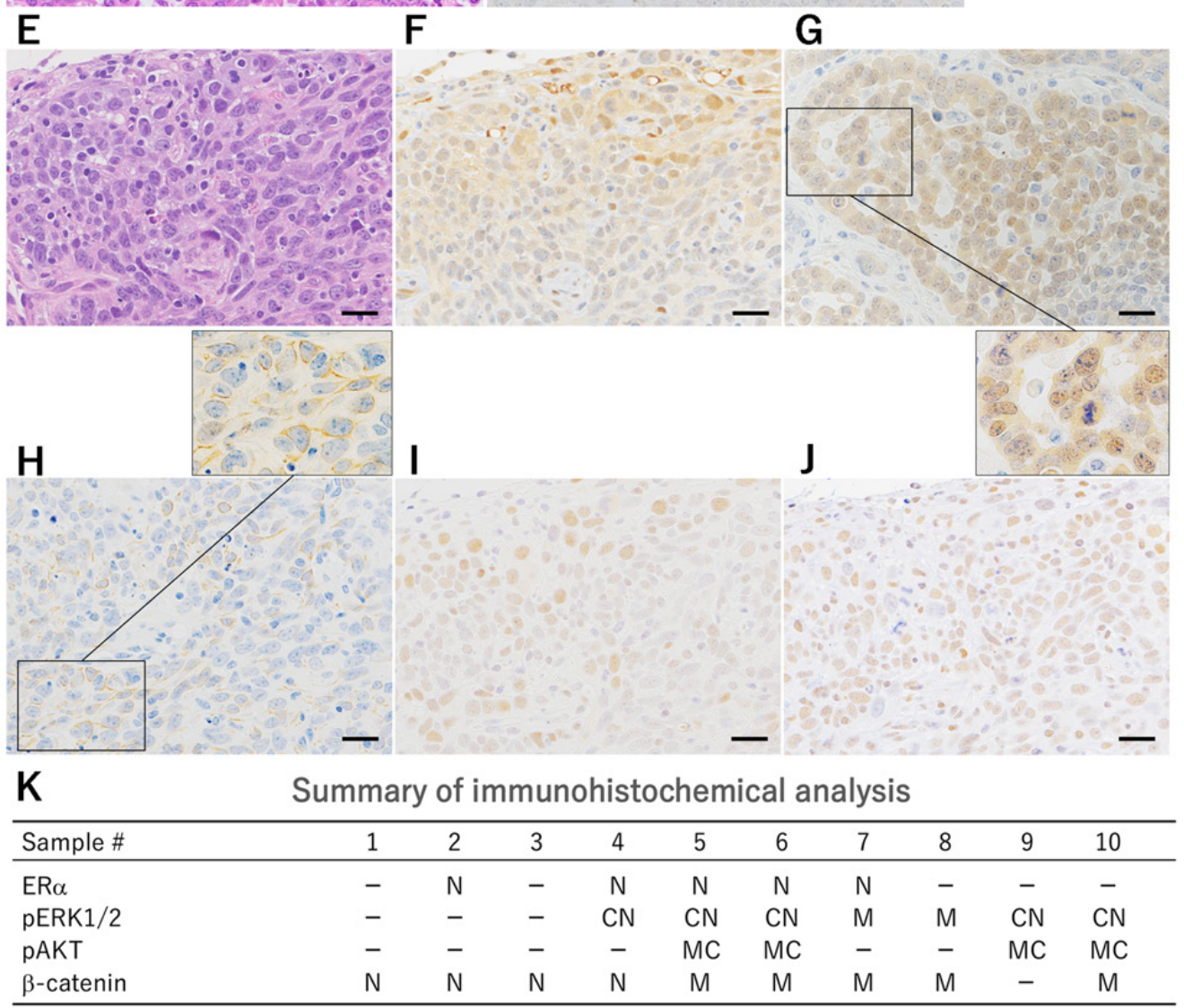

Figure 3. (A) Mammary carcinomas induced in PhIP-treated Trp53 heterozygous knockout mice demonstrated moderately differentiated solid/microacinar structures (H\&E staining; scale bar, $50 \mu \mathrm{m}$ ). (B) Myoepithelial cells positive for $\alpha$ SMA (brown) were scattered among luminal cells; the lower right box is a higher magnification image of the lower right box. (C) Microacinar type with small ductules. H\&E staining; scale bar, $20 \mu \mathrm{m}$. (D) Immunohistochemistry for estrogen receptor $\alpha$ was negative in 5/10 cases. (E) Solid type. H\&E staining; scale bar, $20 \mu \mathrm{m}$. (F) CN positivity for pERK was detected in the peripheral area of the nodules. (G) $\mathrm{CN}$ positivity for $\beta$-catenin was detected; the lower right box is a higher magnification image of the upper left box. (H) M positivity for pAKT was diffusely scattered. The box in the upper right is a higher magnification image of the lower left box. (I) Proliferating cell nuclear antigen is diffusely positive. (J) N positivity for dual-specificity phosphatase is weak. (K) Summary of immunohistochemical analysis of mammary carcinomas in PhIP-treated Trp53 heterozygous knockout mice. PhIP, 2-amino-1-methyl-6-phenylimidazo(4,5-b)pyridine; CN, cytoplasmic and nuclear; N, nuclear; M, membranous; $\mathrm{H} \& \mathrm{E}$, hematoxylin and eosin; $\alpha \mathrm{SMA}, \alpha$-smooth muscle actin.

was primarily detected in the outer cells (Fig. 2H) and pERK positivity in inner mammary carcinoma cells (Fig. 2E). This indicates that DMBA-induced mammary carcinomas in heterozygous Trp53 knockout mice were distinctly characterized by histological biphasic structures, and predominant ER $\alpha$ - and pERK-positivity (Fig. 2J).
Mammary carcinomas induced in the PhIP-treated heterozygous $\operatorname{Tr} 533$ knockout mice demonstrated moderately differentiated solid/microacinar structures (Fig. 3A) and partly papillary patterns, resembling those of spontaneous mammary carcinomas in the heterozygous Trp 53 knockout mice (Fig. S2A) and one carcinoma case from the Trp53 
A

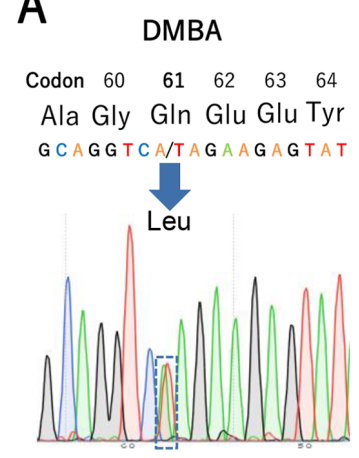

C

DMBA
PhIP

Codon $\quad 6061 \quad 62 \quad 63 \quad 64$ Ala Gly Gln Glu Glu Tyr GCAGGTCAAGAGAGTAT

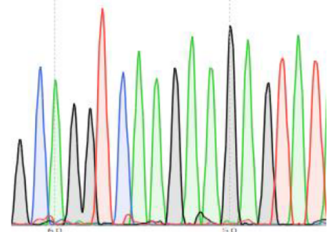

B

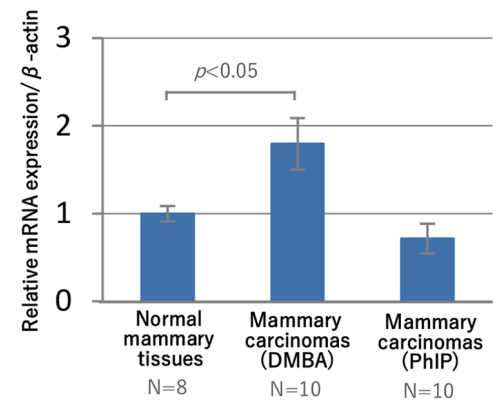

\begin{tabular}{lcccccccccc}
\hline Sample \# & 1 & 2 & 3 & 4 & 5 & 6 & 7 & 8 & 9 & 10 \\
\hline Hras, codon 61 & + & + & + & + & + & + & + & + & + & + \\
Pik3ca, exon 6/7/9/20 & - & - & - & - & - & - & - & - & - & - \\
\hline PhIP & & & & & & & & & & \\
\hline Sample \# & 1 & 2 & 3 & 4 & 5 & 6 & 7 & 8 & 9 & 10 \\
\hline Hras, codon 61 & - & - & - & - & - & - & - & - & - & - \\
Pik3ca, exon 6/7/9/20 & - & - & - & - & - & - & - & - & - & - \\
\hline
\end{tabular}

Figure 4. (A) A Hras codon 61 mutation was observed in carcinomas of DMBA-treated mice but not in those of PhIP-treated mice. (B) RT-qPCR showed an increased Dusp4 expression in carcinomas of the DMBA-treated group, compared with that in the PhIP-treated group and normal mammary tissues (bar=SE). (C) Summary of gene mutation analysis of mammary carcinomas in DMBA- or PhIP-treated Trp53 heterozygous knockout mice. Hras, HRas proto-oncogene; DMBA, 7,12-dimethylbenz[a]anthracene; PhIP, 2-amino-1-methyl-6-phenylimidazo(4,5-b)pyridine; RT-qPCR, reverse transcription-quantitative PCR; Dusp4, dual-specificity phosphatase.

wild-type group without DMBA administration (data not shown). Immunohistochemically, $\alpha$ SMA-positive myoepithelial cells were not observed or found to be scattered in various degrees among luminal cells (Fig. 3B). Among the 10 selected large carcinoma samples in the PhIP-treated heterozygous Trp53 knockout mice, 6, 4, 0, 0 and 0 cases were classified into grades $0,1,2,3$ and 4 , respectively, based on the biphasic characteristics.

The results of IHC for signaling molecules in the PhIP-treated heterozygous $\operatorname{Tr} p 53$ knockout mice are shown in Fig. 3D and F-3J and summarized in Fig. 3K. In $\mathrm{H} \& \mathrm{E}$-stained specimens, cellular atypia with nuclear enlargement and pleomorphism in the PhIP-treated heterozygous Trp53 knockout mice was more conspicuous (Fig. 3C and E) than in mice without chemical treatment in the heterozygous Trp53 knockout mice (Fig. S2A) and one carcinoma case from the Trp53 wild-type group without DMBA administration (data not shown). IHC for ER $\alpha$ revealed $\mathrm{N}$ positivity, and the incidence of ER $\alpha$-positive and -negative carcinomas was 5/10 each in PhIP-treated mice (Fig. 3D). pERK exhibited $\mathrm{CN}(5 / 10)$ (Fig. 3F) and $\mathrm{M}(2 / 10)$ positivity in the peripheral area of the nodules. IHC for $\beta$-catenin revealed $M(5 / 10)$ and $\mathrm{N}$ (4/10) positivity in the carcinoma cells (Fig. 3G). With regards to pAKT, $\mathrm{M}$ or $\mathrm{C}$ positivity was observed in $4 / 10$ PhIP-treated mice (Fig. 3H). PCNA positivity was diffusely detected (Fig. 3I) in the carcinoma tissues of PhIP-treated mice. No obvious association between histopathological types (solid, microacinar structures or papillary patterns) and IHC characteristics was observed in mammary carcinomas from the PhIP group. In summary, mammary carcinomas induced in PhIP-treated heterozygous Trp53 knockout mice exhibited different molecular markers, indicating Wnt/ $\beta$-catenin signaling and/or PI3K/AKT signaling activation (Fig. 3K).

DMBA-induced mammary tumors exhibit high-frequency Hras mutations and stimulate MAPK signaling. Direct DNA sequencing revealed a missense mutation from CAA to CTA transversion (Gln to Leu) at exon 2, codon 61 of the Hras gene (Fig. 4A) in the mammary carcinomas of DMBA-treated mice (10/10), which was consistent with the findings of a previous study (39). PhIP-treated mice exhibited no such Hras mutation.

To confirm the activation of the MAPK signaling pathway in DMBA-induced mammary carcinomas, the expression levels of Dusp4, a negative regulator of the MAPK signaling pathway, were examined. RT-qPCR revealed higher Dusp4 expression in carcinoma tissues from DMBA-treated mice than in normal mammary tissues $(\mathrm{P}<0.05)$ from mice without DMBA administration (Fig. 4B). Also in IHC for DUSP4, diffuse $\mathrm{N}$ positivity in 10/10 DMBA-treated mice (Fig. 2I) and weak N positivity in PhIP-treated mice (Fig. 3J) were observed. PIK3CA (human)/Pik3ca (mouse) mutations at several hot spots, which are found in human breast carcinoma (Fig. S1B), were reported in DMBA-treated CD2F1 mice (10), but no Pik3ca mutation was detected in the carcinomas of DMBAand PhIP-treated heterozygous BALB/c Trp53 knockout mice (Fig. 4C). These results showed that DMBA-induced mammary carcinomas were clearly characterized by Hras mutation at a high frequency, and gene/protein expression indicating MAPK stimulation. 


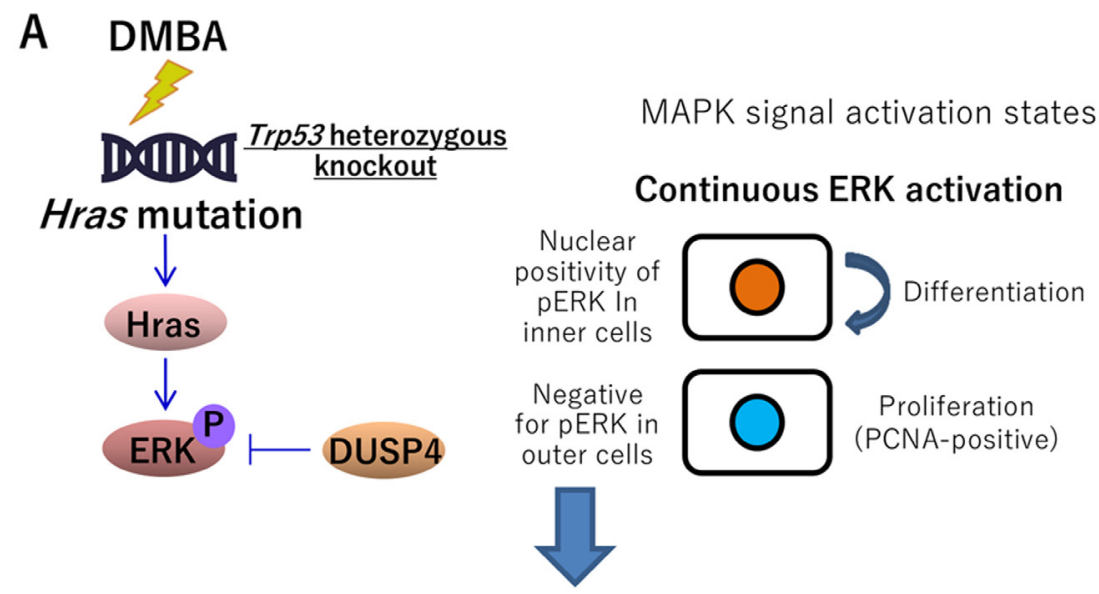

Highly differentiated (Biphasic structures)

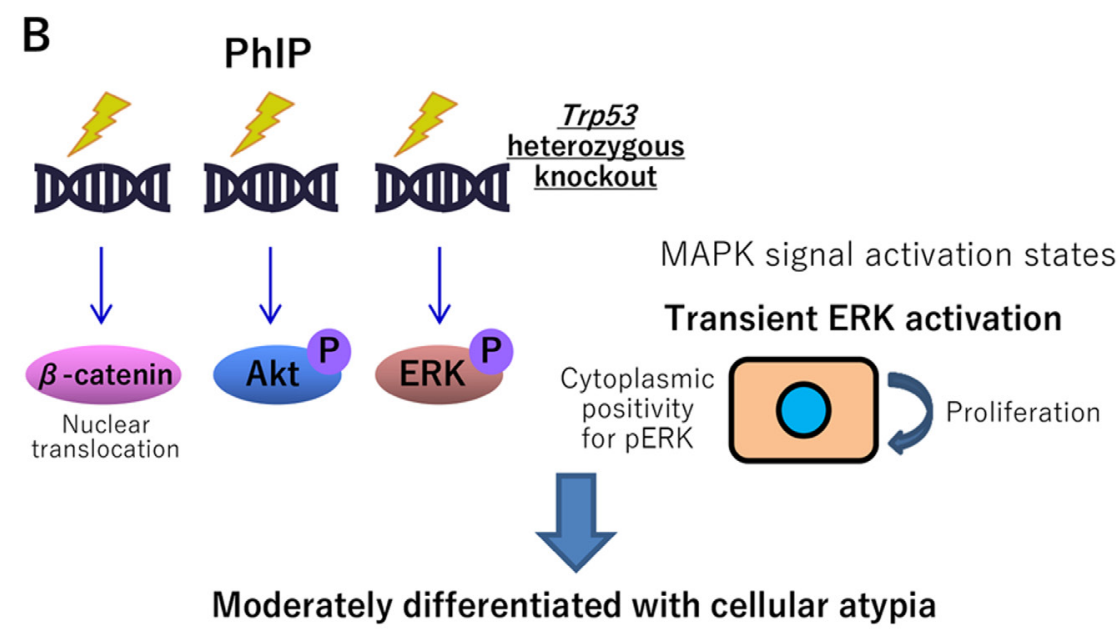

Figure 5. Predicted molecular mechanisms of mammary carcinogenesis by DMBA and PhIP in BALB/c Trp53 heterozygous knockout mice. (A) DMBA induces Hras mutation and activates MAPK signaling. Continuous ERK activation resulted in cellular differentiation. (B) Several signaling pathways were activated in PhIP-treated carcinomas, resulting in cellular atypia. DMBA, 7,12-dimethylbenz[a]anthracene; Hras, HRas proto-oncogene; PhIP, 2-amino-1-methyl-6-phenyli midazo(4,5-b)pyridine; Trp53, tumor protein $\mathrm{p} 53$.

\section{Discussion}

The primary aim of the present study was to confirm whether DMBA or PhIP promoted mammary carcinogenesis in heterozygous BALB/c Trp53 knockout mice. It was found that DMBA administration significantly accelerated the induction of mammary carcinomas in heterozygous Trp 53 knockout mice, and the terminal incidence in wild-type mice was lower than that in heterozygous Trp53 knockout mice. A previous study reported no differences in susceptibility to mammary tumors following DMBA administration between heterozygous BALB/c Trp53 knockout and Trp53 wild-type mice (40), but the doses and treatment schedule, as well as internal hormonal conditions, differed from those in the present study. A significant reduction in 553 function has been observed in heterozygous Trp53 knockout mice compared with wild-type mice (41). In addition, the study indicated that carcinogenesis in the Trp 53 heterozygous knockout mice was likely to involve numerous carcinogen-tissue interactions that determine the tumor origin site and latency to tumor formation, and the wild-type Trp53 allele was frequently retained in induced tumors (41). The tumor suppressor p53 plays an essential role during the cellular response to DNA damage by regulating several cellular processes, such as cell cycle arrest, apoptosis and DNA repair (42). Genomic instability associated with heterozygous $\operatorname{Trp} 53$ knockout is considered to cause DMBA-induced gene mutations. In the PhIP group, the median latency period of mammary carcinomas was 40-41 weeks of age, and it was slightly shorter at $\geq 50$ weeks of age for spontaneous cases during the lifetime observation of heterozygous BALB/c Trp53 knockout mice $(24,25)$. In wild-type BALB/c mice, the survival period for mice with mammary carcinomas was $>65$ and $>75$ weeks in the PhIP-treated and non-treated control groups, respectively (43). The present study demonstrated that the increased susceptibility to mammary carcinogenesis was due to the combination of Trp53 gene function deficiency and exogenous factors.

Another important aim of the present study was to investigate the phenotypic and genotypic characteristics of the induced carcinomas with reference to published data on human breast cancer. DMBA-induced mammary carcinomas histopathologically exhibited distinct biphasic structures with luminal and myoepithelial cells. The majority (62\%) of spontaneous mammary tumors identified during the lifetime observation of heterozygous BALB/c Trp53 knockout mice were reported to 
exhibit a mixture of luminal and myoepithelial cells, while other tumors were reported to exhibit luminal or basal/myoepithelial cells only (25). Furthermore, DMBA-induced mammary tumors in $\mathrm{B} 6 \mathrm{D} 2 \mathrm{~F} 1$ mice were reported to exhibit bicellular characteristics at a rate of $29 \%$ (11), suggesting that the distinct biphasic structures of DMBA-induced mammary tumors are enhanced in heterozygous Trp53 knockout mice. Among human breast tumors, adenomyoepithelioma is characterized as a stereotypical epithelial-myoepithelial tumor composed of myoepithelial cells surrounding epithelial tissue-lined spaces $(44,45)$. There are histopathological differences between DMBA-induced rodent adenocarcinomas and human adenomyoepithelioma. For example, in the former, inner epithelial components are predominant and multilayered, and the outer myoepithelium is single or bilayered; while in the latter, myoepithelial components are predominant, and surround simple ductal structures. As compared with spontaneous mammary carcinomas in another lifetime study of BALB/c-Trp53 heterozygous knockout mice without DMBA/PhIP administration (24), PhIP-induced mammary carcinomas demonstrated solid/microacinar structures with more prominent cellular atypia and pleomorphism. Therefore, both the DMBA-induced cases, and the modestly accelerated induction of mammary carcinomas by PhIP, were suspected to be influenced by genetic or epigenetic events.

Of note, Hras mutation at exon 2, codon 61 was frequently observed in the DMBA-induced mammary carcinomas in heterozygous Trp53 knockout mice in the present study. A characteristically active mutation, $\mathrm{A}$ to $\mathrm{T}$ transversion, at the middle adenosine nucleotide in codon 61 following DMBA treatment in the BALB/c mouse mammary gland, has previously been reported (46). In CDF1 mice, the Hras mutation in codon 61 was detected in 1/9 (11\%) of mammary carcinomas during long-latency periods following DMBA administration (10), and the facilitation of Hras mutation at a frequency of $10 / 10(100 \%)$ in the present study suggested molecular mechanisms underlying the acceleration of the induction or selection of the mutation in Trp53 heterozygous knockout mice compared with wild-type $(39,46)$. Indeed, when the p53 R273H mutation occurred within RasV12-transformed epithelia, cell death was strongly suppressed, and the majority of p53 R273H-expressing cells survived (47). Mutations in the Hras oncogenes in mammary tumors and mammary hyperplasic outgrowth from DMBA-treated mice were confined to codon 61 substitutions of A to $\mathrm{T}$ or G (39). An incidence of $20 \%$ of the Hras mutations at codon 61 were also reported in DMBA-induced mammary carcinomas in rats $(34,35)$, but the frequency in heterozygous Trp53 knockout mice in the present study was higher.

HRAS activation is uncommon, and PIK3CA mutations, which were detected in $45 \%$ of the luminal A [HR-positive, progesterone receptor-high, HER2-negative] subtype, were associated with the induction and/or poor outcome of human breast cancer $(36,48)$. On the other hand, mutations in both $H R A S$ and PI3K/AKT pathway genes, including PIK3CA, were recently reported as drivers of breast adenomyoepitheliomas (49,50). The associations between HRAS (human)/Hras (mouse) mutations and the composition of carcinoma cells with luminal and myoepithelial lineages in human adenomyoepitheliomas and DMBA-induced mouse mammary carcinomas are not clear. However, in the present study, DMBA-induced mammary carcinomas with a high-frequency Hras mutation may partly function as a model of adenomyoepithelioma. The IHC results of the DMBA-induced mammary carcinomas in heterozygous Trp53 knockout mice showed a high frequency of ER $\alpha$-positive cells (suggesting HR-positive breast cancer) and $\mathrm{N}$ positivity for $\mathrm{pERK}$, indicating the continuous stimulation of the MAPK signaling pathway (51). The continuous stimulation of MAPK leads to cellular differentiation, while transient stimulation induces cellular proliferation (Fig. 5) (52). In the present DMBA-induced carcinomas, PCNA was positively expressed primarily in pERK-negative cells, which was consistent with a previous report (52). In a previous cDNA microarray analysis of DMBA-induced mammary carcinomas in female Sprague-Dawley rats, the MAPK-modulation gene DUSP, which functions in the dephosphorylation and/or sequestration of ERK, JNK and p38 kinases (53), was the predominantly expressed clone (54). The present RT-qPCR analysis revealed that the expression level of Dusp4 was high in DMBA-induced mammary carcinomas, suggesting that the activation of the MAPK signaling pathway is negatively regulated by increased Dusp 4 expression. As for the mutations in Pik3ca exons 6, 7, 9 and 20, no mutation was found in the DMBA-induced mammary carcinomas in heterozygous BALB/c Trp53 knockout mice. Abba et al (10) demonstrated that Pik3ca mutations at a hot spot in human breast carcinomas were also detected in mammary carcinomas induced in CDF1 mice during long-latency periods following DMBA administration, but not in mammary carcinomas induced in the same mouse strain after a short-latency period following progestin medroxyprogesterone acetate plus DMBA administration.

Based on the IHC findings of mammary carcinomas in the present DMBA-treated heterozygous BALB/c Trp53 knockout mice, the incidence of ER $\alpha$-positive carcinomas appeared to be increased, compared with that in spontaneous mammary carcinomas (Fig. S2) (24), and no obvious differences were observed in the positivity of pERK, $\beta$-catenin and pAKT. On the other hand, in PhIP-treated heterozygous BALB/c Trp53 knockout mice, multiple molecular mechanisms for carcinogenesis (Fig. 5), including the activation of the Wnt/ $\beta$-catenin, PI3K/AKT and MAPK signaling pathways, e.g., N positivity for $\beta$-catenin, $\mathrm{MC}$ positivity for $\mathrm{pAKT}$, and $\mathrm{CN}$ positivity for pERK, respectively, were exhibited in comparison with those in spontaneous mammary carcinomas (Fig. S2) (24). However, no mutations were found in Pik3ca exons 6, 7,9 and 20, or in Hras exon 2, codon 61. This may have been due to the fact that pAKT, a typical marker of PI3K/AKT pathway activation, was not increased in Pik3ca-mutated luminal A subtype cancer. It was instead highly prevalent in the basal-like (HR-negative, HER2-negative) and HER2-enriched (HR-negative, HER2-positive) subtypes $(36,55)$. To the best of our knowledge, there are no reports suggesting an association between the Wnt $/ \beta$-catenin signaling pathway and mammary carcinogenesis. In human breast cancer, no gene mutation associated with the Wnt signaling pathway has been reported (36), but the epigenetic inactivation of Wnt antagonist genes, such as secreted frizzled-related protein 1 , has been reported $(56,57)$. In-depth evaluation to clarify the underlying genetic mechanisms was not included in the present study. Therefore, further investigation of the carcinoma tissues (including genome-wide mutation sequencing or methylation analysis), is required to clarify the molecular mechanisms underlying the acceleration of mammary carcinogenesis, particularly by PhIP administration. 
In conclusion, the present mouse mammary carcinogenesis models induced by a combination of genetic and exogenous factors may be utilized (such as the DMBA-induced model with Trp53 gene function deficiency as a model of adenomyoepithelioma characterized by distinct biphasic cell constituents and Hras mutations), but PhIP-induced models are required to further analyze the other genetic/epigenetic mechanisms promoting mammary carcinomas.

\section{Acknowledgements}

The authors would like to thank the Animal Core Facility of the National Cancer Center Research Institute for maintaining the mice, and for their technical support in histopathological evaluations. The Core Facility was supported by the National Cancer Center Research and Development Fund (2020-J-002). In addition, the authors would like to thank Ms. Sudo Yukiko, Mr. Shun Ito, Ms. Ruri Nakanishi, Ms. Naoko Higashijima, Mr. Naoaki Uchiya and Ms. Yurika Shiotani (Central Animal Division National Cancer Center Research Institute, Tokyo, Japan), for their technical assistance.

\section{Funding}

The present study was supported in part by a Health and Labour Sciences Research Grant from the Ministry of Health, Labour and Welfare of Japan (grant no. H30-Food-003), the National Cancer Center Research and Development Fund (grant no. 2020-J-002), and Grants-in-Aid for Scientific Research (JSPS KAKENHI, grant no. JP19H01610).

\section{Availability of data and materials}

The datasets used and/or analyzed during the current study are available from the corresponding author on reasonable request.

\section{Authors' contributions}

YM carried out the experiments, contributed to the analysis and interpretation of data, and drafted, read and approved the final manuscript. TI contributed to developing the overall strategies and concepts, and was responsible for the study design, data analysis and manuscript finalization. YM and TI confirmed the authenticity of all the raw data. All authors have read and approved the final manuscript.

\section{Ethics approval and consent to participate}

The animal experiments and procedures were approved by the National Cancer Center Animal Ethics Committee (approval no. T17-028-C02).

\section{Patient consent for publication}

Not applicable.

\section{Competing interests}

The authors declare that they have no competing interests.

\section{References}

1. Fidler MM, Gupta S, Soerjomataram I, Ferlay J, SteliarovaFoucher E and Bray F: Cancer incidence and mortality among young adults aged 20-39 years worldwide in 2012: A population-based study. Lancet Oncol 18: 1579-1589, 2017.

2. Johnson RH, Chien FL and Bleyer A: Incidence of breast cancer with distant involvement among women in the United States, 1976 to 2009. JAMA 309: 800-805, 2013.

3. DeSantis CE, Ma J, Gaudet MM, Newman LA, Miller KD, Goding Sauer A, Jemal A and Siegel RL: Breast cancer statistics, 2019. CA Cancer J Clin 69: 438-451, 2019.

4. Kataoka A, Iwamoto T, Tokunaga E, Tomotaki A, Kumamaru H, Miyata H, Niikura N, Kawai M, Anan K, Hayashi N, et al: Young adult breast cancer patients have a poor prognosis independent of prognostic clinicopathological factors: A study from the Japanese Breast Cancer Registry. Breast Cancer Res Treat 160: 163-172, 2016.

5. Imai T, Cho YM, Takahashi M, Kitahashi T, Takami S, Nishikawa A and Ogawa K: High susceptibility of heterozygous (+/fa) lean Zucker rats to 7,12-dimethylbenz(a)anthracene-induced mammary carcinogenesis. Oncol Rep 29: 1914-1922, 2013.

6. Kaga C, Takagi A, Kano M, Kado S, Kato I, Sakai M, Miyazaki K, Nanno M, Ishikawa F, Ohashi Y, et al: Lactobacillus casei Shirota enhances the preventive efficacy of soymilk in chemically induced breast cancer. Cancer Sci 104: 1508-1514, 2013.

7. Dabydeen SA and Furth PA: Genetically engineered ER $\alpha$-positive breast cancer mouse models. Endocr Relat Cancer 21: R195-R208, 2014.

8. Huggins C, Grand LC and Brillantes FP: Mammary cancer induced by a single feeding of polymucular hydrocarbons, and its suppression. Nature 189: 204-207, 1961.

9. Russo J, Gusterson BA, Rogers AE, Russo IH, Wellings SR and van Zwieten MJ: Comparative study of human and rat mammary tumorigenesis. Lab Invest 62: 244-278, 1990.

10. Abba MC, Zhong Y, Lee J, Kil H, Lu Y, Takata Y, Simper MS, Gaddis S, Shen J and Aldaz CM: DMBA induced mouse mammary tumors display high incidence of activating Pik3caH1047 and loss of function Pten mutations. Oncotarget 7: 64289-64299, 2016.

11. Rehm S: Chemically induced mammary gland adenomyoepitheliomas andmyoepithelialcarcinomas of mice.Immunohistochemical and ultrastructural features. Am J Pathol 136: 575-584, 1990.

12. Hasegawa R, Sano M, Tamano S, Imaida K, Shirai T, Nagao M, Sugimura T and Ito N: Dose-dependence of 2-amino-1-methyl6-phenylimidazo[4,5-b]-pyridine (PhIP) carcinogenicity in rats. Carcinogenesis 14: 2553-2557, 1993.

13. Shirai T, Sano M, Tamano S, Takahashi S, Hirose M,Futakuchi M, Hasegawa R, Imaida K, Matsumoto K, Wakabayashi K, et al: The prostate: A target for carcinogenicity of 2-amino-1-methy 1-6-phenylimidazo[4,5-b]pyridine (PhIP) derived from cooked foods. Cancer Res 57: 195-198, 1997.

14. Nakagama H, Ochiai M, Ubagai T, Tajima R, Fujiwara K, Sugimura T and Nagao M: A rat colon cancer model induced by 2-amino-1-methyl-6-phenylimidazo[4,5-b]pyridine, PhIP. Mutat Res 506-507: 137-144, 2002.

15. Ghoshal A, Preisegger KH, Takayama S, Thorgeirsson SS and Snyderwine EG: Induction of mammary tumors in female Sprague-Dawley rats by the food-derived carcinogen 2-amino-1methyl-6-phenylimidazo[4,5-b]pyridine and effect of dietary fat. Carcinogenesis 15: 2429-2433, 1994.

16. Ip C, Carter CA and Ip MM: Requirement of essential fatty acid for mammary tumorigenesis in the rat. Cancer Res 45: 1997-2001, 1985.

17. Welsch CW: Relationship between dietary fat and experimental mammary tumorigenesis: A review and critique. Cancer Res 52 (Suppl 7): 2040s-2048s, 1992.

18. Jiang Y, Pan Y, Rhea PR, Tan L, Gagea M, Cohen L, Fischer SM and Yang P: A sucrose-enriched diet promotes tumorigenesis in mammary gland in part through the 12-Lipoxygenase pathway. Cancer Res 76: 24-29, 2016.

19. Lo CY, Hsieh PH, Chen HF and Su HM: A maternal high-fat diet during pregnancy in rats results in a greater risk of carcinogen-induced mammary tumors in the female offspring than exposure to a high-fat diet in postnatal life. Int J Cancer 125: 767-773, 2009.

20. Grassi TF, Bidinotto LT, Lopes GA, Zapaterini JR, Rodrigues MA and Barbisan LF: Maternal western-style diet enhances the effects of chemically-induced mammary tumors in female rat offspring through transcriptome changes. Nutr Res 61: 41-52, 2019. 
21. Macacu A, Autier P, Boniol M and Boyle P: Active and passive smoking and risk of breast cancer: A meta-analysis. Breast Cancer Res Treat 154: 213-224, 2015.

22. Hecht SS: Tobacco smoke carcinogens and breast cancer. Environ Mol Mutagen 39: 119-126, 2002

23. Engin A: Obesity-associated breast cancer: Analysis of risk factors. Adv Exp Med Biol 960: 571-606, 2017.

24. Machida Y, Sudo Y, Uchiya N and Imai T: Increased susceptibility to mammary carcinogenesis and an opposite trend in endometrium in Trp53 heterozygous knockout female mice by backcrossing the $\mathrm{BALB} / \mathrm{c}$ strain onto the background $\mathrm{C} 3 \mathrm{H}$ strain. J Toxicol Pathol 32: 197-203, 2019.

25. Yan H, Blackburn AC, McLary SC, Tao L, Roberts AL, Xavier EA, Dickinson ES, Seo JH, Arenas RB, Otis CN, et al: Pathways contributing to development of spontaneous mammary tumors in BALB/c-Trp53+/- mice. Am J Pathol 176: 1421-1432, 2010.

26. Tsukada T, Tomooka Y, Takai S, Ueda Y, Nishikawa S, Yagi T, Tokunaga T, Takeda N, Suda Y, Abe S, et al: Enhanced proliferative potential in culture of cells from p53-deficient mice. Oncogene 8: 3313-3322, 1993.

27. Ueda M, Imai T, Takizawa T, Onodera H, Mitsumori K, Matsui T and Hirose M: Possible enhancing effects of atrazine on growth of 7,12-dimethylbenz(a) anthracene-induced mammary tumors in ovariectomized Sprague-Dawley rats. Cancer Sci 96: 19-25, 2005.

28. el-Bayoumy K, Chae YH, Upadhyaya P, Rivenson A, Kurtzke C, Reddy B and Hecht SS: Comparative tumorigenicity of benzo[a] pyrene, 1-nitropyrene and 2-amino-1-methyl-6-phenylimida zo[4,5-b]pyridine administered by gavage to female CD rats. Carcinogenesis 16: 431-434, 1995.

29. Snyderwine EG, Thorgeirsson UP, Venugopal $M$ and Roberts-Thomson SJ: Mammary gland carcinogenicity of 2-amin o-1-methyl-6-phenylimidazo[4,5-b]pyridine in Sprague-Dawley rats on high- and low-fat diets. Nutr Cancer 31: 160-167, 1998.

30. Imaoka T, Nishimura M, Doi K, Tani S, Ishikawa K, Yamashita S, Ushijima T, Imai T and Shimada Y: Molecular characterization of cancer reveals interactions between ionizing radiation and chemicals on rat mammary carcinogenesis. Int J Cancer 134: $1529-1538,2014$

31. Workman P, Aboagye EO, Balkwill F, Balmain A, Bruder G Chaplin DJ, Double JA, Everitt J, Farningham DA, Glennie MJ, et al Committee of the National Cancer Research Institute: Guidelines for the welfare and use of animals in cancer research. Br J Cancer 102: 1555-1577, 2010.

32. Cardiff RD, Anver MR, Gusterson BA, Hennighausen L, Jensen RA, Merino MJ, Rehm S, Russo J, Tavassoli FA, Wakefield LM, et al: The mammary pathology of genetically engineered mice: The consensus report and recommendations from the Annapolis meeting. Oncogene 19: 968-988, 2000

33. Rudmann D, Cardiff R, Chouinard L, Goodman D, Küttler K, Marxfeld H, Molinolo A, Treumann S and Yoshizawa K; INHAND Mammary, Zymbal's, Preputial, and Clitoral Gland Organ Working Group: Proliferative and nonproliferative lesions of the rat and mouse mammary, Zymbal's, preputial, and clitoral glands. Toxicol Pathol 40 (Suppl 6): 7S-39S, 2012.

34. Kito K, Kihana T, Sugita A, Murao S, Akehi S, Sato M, Tachibana M, Kimura S and Ueda N: Incidence of p53 and Ha-ras gene mutations in chemically induced rat mammary carcinomas. Mol Carcinog 17: 78-83, 1996.

35. El-Sohemy A and Archer MC: Inhibition of N-methyl-Nnitrosourea- and 7,12-dimethylbenz[a] anthracene-induced rat mammary tumorigenesis by dietary cholesterol is independent of Ha-Ras mutations. Carcinogenesis 21: 827-831, 2000.

36. Cancer Genome Atlas Network: Comprehensive molecular portraits of human breast tumours. Nature 490: 61-70, 2012.

37. Livak KJ and Schmittgen TD: Analysis of relative gene expression data using real-time quantitative PCR and the 2(-Delta Delta C(T)) method. Methods 25: 402-408, 2001.

38. Kanda Y: Investigation of the freely available easy-to-use software 'EZR' for medical statistics. Bone Marrow Transplant 48: 452-458, 2013.

39. Kumar R, Medina D and Sukumar S: Activation of H-ras oncogenes in preneoplastic mouse mammary tissues. Oncogene 5: 1271-1277, 1990

40. Jerry DJ, Butel JS, Donehower LA, Paulson EJ, Cochran C, Wiseman RW and Medina D: Infrequent p53 mutations in 7,12-dimethylbenz[a]anthracene-induced mammary tumors in BALB/c and p53 hemizygous mice. Mol Carcinog 9: 175-183, 1994.
41. Venkatachalam S, Tyner SD, Pickering CR, Boley S, Recio L, French JE and Donehower LA: Is 553 haploinsufficient for tumor

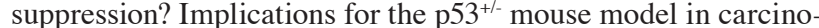
genicity testing. Toxicol Pathol 29 (Suppl 1): 147-154, 2001.

42. Hollstein $M$ and Hainaut P: Massively regulated genes: The example of TP53. J Pathol 220: 164-173, 2010.

43. Nagao M, Ushijima T, Watanabe N, Okochi E, Ochiai M, Nakagama $\mathrm{H}$ and Sugimura T: Studies on mammary carcinogenesis induced by a heterocyclic amine, 2-amino-1-methyl-6 -phenylimidazo[4,5-b]pyridine, in mice and rats. Environ Mol Mutagen 39: 158-164, 2002.

44. Tan PH and Ellis IO: Myoepithelial and epithelial-myoepithelial, mesenchymal and fibroepithelial breast lesions: Updates from the WHO Classification of Tumours of the Breast 2012. J Clin Pathol 66: 465-470, 2013.

45. McLaren BK, Smith J, Schuyler PA, Dupont WD and Page DL: Adenomyoepithelioma: Clinical, histologic, and immunohistologic evaluation of a series of related lesions. Am J Surg Pathol 29: 1294-1299, 2005.

46. Cardiff RD, Gumerlock PH, Soong MM, Dandekar S, Barry PA, Young LJ and Meyers FJ: c-H-ras-1 expression in 7,12-dimethyl benzanthracene-induced Balb/c mouse mammary hyperplasias and their tumors. Oncogene 3: 205-213, 1988.

47. Watanabe H, Ishibashi K, Mano H, Kitamoto S, Sato N, Hoshiba K, Kato M, Matsuzawa F, Takeuchi Y, Shirai T, et al: Mutant p53-expressing cells undergo necroptosis via cell competition with the neighboring normal epithelial cells. Cell Rep 23: 3721-3729, 2018

48. Ramirez-Ardila D, Timmermans AM, Helmijr JA, Martens JW, Berns EM and Jansen MP: Increased MAPK $1 / 3$ phosphorylation in luminal breast cancer related with PIK3CA hotspot mutations and prognosis. Transl Oncol 10: 854-866, 2017.

49. Geyer FC,Li A,Papanastasiou AD, Smith A, SelenicaP,Burke KA Edelweiss M, Wen HC, Piscuoglio S, Schultheis AM, et al: Recurrent hotspot mutations in HRAS Q61 and PI3K-AKT pathway genes as drivers of breast adenomyoepitheliomas. Nat Commun 9: 1816, 2018.

50. Ginter PS, McIntire PJ, Kurtis B, Mirabelli S, Motanagh S, Hoda S, Elemento O, Shin SJ and Mosquera JM: Adenomyoepithelial tumors of the breast: Molecular underpinnings of a rare entity. Mod Pathol 33: 1764-1772, 2020.

51. Kato S, Endoh H, Masuhiro Y, Kitamoto T, Uchiyama S, Sasaki H, Masushige S, Gotoh Y, Nishida E, Kawashima H, et al: Activation of the estrogen receptor through phosphorylation by mitogen-activated protein kinase. Science 270: 1491-1494, 1995.

52. Marshall CJ: Specificity of receptor tyrosine kinase signaling: Transient versus sustained extracellular signal-regulated kinase activation. Cell 80: 179-185, 1995.

53. Owens DM and Keyse SM: Differential regulation of MAP kinase signalling by dual-specificity protein phosphatases. Oncogene 26: 3203-3213, 2007

54. Shan L, He M, Yu M, Qiu C, Lee NH, Liu ET and Snyderwine EG: cDNA microarray profiling of rat mammary gland carcinomas induced by 2-amino-1-methyl-6-phenylimidazo[4,5-b]pyridine and 7,12-dimethylbenz[a]anthracene. Carcinogenesis 23: 1561-1568, 2002

55. SakrRA, WeigeltB,Chandarlapaty $S$, Andrade VP, Guerini-RoccoE, Giri D, Ng CK, Cowell CF, Rosen N, Reis-Filho JS, et al: PI3K pathway activation in high-grade ductal carcinoma in situ - implications for progression to invasive breast carcinoma. Clin Cancer Res 20: 2326-2337, 2014

56. Veeck J, Niederacher D, An H, Klopocki E, Wiesmann F, Betz B, Galm O, Camara O, Dürst M, Kristiansen G, et al: Aberrant methylation of the Wnt antagonist SFRP1 in breast cancer is associated with unfavourable prognosis. Oncogene 25: 3479-3488, 2006.

57. Suzuki H, Toyota M, Carraway H, Gabrielson E, Ohmura T, Fujikane T, Nishikawa N, Sogabe Y, Nojima M, Sonoda T, et al: Frequent epigenetic inactivation of Wnt antagonist genes in breast cancer. Br J Cancer 98: 1147-1156, 2008

This work is licensed under a Creative Commons Attribution-NonCommercial-NoDerivatives 4.0 International (CC BY-NC-ND 4.0) License. 